\title{
THE MATURE LARVA AND PUPARIUM OF PHYSOCEPHALA SAGITTARIA (SAY) (DIPTERA, CONOPID E) ${ }^{1}$
}

\author{
By Lee H. Townsend \\ Illinois State Natural History Survey, Urbana
}

The larvæ of the Conopidæ, so far as known, are parasitic upon other insects, living within the body and consuming the non-vital parts. The larvæ pupate here also, pass the winter in this stage and the adults emerge the following spring or summer.

There are many more records of these parasitic flies in European than in American literature. Brauer (1883) listed the literature concerning the immature stages and biology. He also gives the family characters, as understood by him, for the larvæ. According to de Meijere (1903), these characters, as given by Brauer, do not hold true for the larvæ of the three known genera. Since Brauer mentioned the anterior spiracles, it seems he must have had a specimen of the conopid genus Sicus. This should be borne in mind when using his description. Williston (1885) gives a translation of Brauer's characters. In two papers de Meijere $(1903,1912)$ compiled all published information on the biology of the family and added much new material. These papers are indispensable to anyone studying the biology of the group. In his account of the family, Brunetti (1923) makes some general statements concerning the larvæ and their life history. He adds nothing new. In 1926, Silvestri described a conopid larva from a specimen of Termes gilvus Hagen received from the Philippines. The species was not known. This larva was living in the head of the termite and is apparently the only case so recorded.

${ }^{1}$ Contributions from the Entomological Laboratories of the University of Illinois, No. 173. 
As reported, the species are parasitic upon various genera of bees, wasps, ants, termites, and grasshoppers. Brauer (l. c.) gives a list of the genera from which these parasitic flies had been reported and very little has been added since. Brauer's list of host genera was copied by Williston (l. c.). The genus Stylogaster is probably parasitic upon ants of the genus Eciton. Aldrich (1930) gives information received from Dr. Wm. Mann and Dr. C. H. Curran concerning the habits of adults with reference to armies of moving ants in Central America. Only one genus (CEdipoda) of Orthoptera has been reported as parasitized by the Conopidæ. The termite record of Silvestri is the only authentic one available. Bates (1863) has been credited with saying in his Naturalist on the River Amazons (vol. 1) that these larvæ attack termites but Aldrich (l. c.) states that he could find no such reference in any of Bates' works. Frison (1926) reported the rearing of Physocephala sagittaria (Say) (det. J. R. Malloch) from the abdomen of dead workers of Bremus auricomus (Robts.). The same author (1930) recorded this parasite from Bremus americanorum (Fabr.).

The material upon which this paper is based was reared from workers of B. auricomus (Robts.) by Dr. T. H. Frison, Chief of the Illinois State Natural History Survey, and to him the writer expresses sincere thanks for being permitted to describe it. The writer wishes also to thank Dr. C. O. Mohr, Associate Entomologist, Illinois State Natural History Survey, who drew figures 1, 4, 5, and 6 .

Mature larva. - The larva (fig. 4) has a broad, somewhat rounded body. The cephalic portion, or head and thoracic region, is much narrowed and being somewhat extensible, projects from the body much as a snout. This portion can be varied in thickness by the larva. The larva can be described as being typically pyriform. Relaxed and extended it measures approximately $13 \mathrm{~mm}$. in length and $5 \mathrm{~mm}$. in breadth at the widest portion. The narrowest cephalic portion is approximately $1 \mathrm{~mm}$. wide. The body narrows to approximately $3 \mathrm{~mm}$. at the location of the posterior spiracles.

The color is yellowish white. No attempt has been made 
to determine the actual number of body segments. It is evident enough that there are eight segments which compose the posterior widened portion. Anterior to these eight there are several more, probably three, which make up the narrowed snout-like anterior portion of the body.

On each side and above the mouth there is a short, broad, pointed projection (figs. 7, 8, p). These structures probably bear sense organs. The mouth $(m)$ is immediately below and between these cephalic projections and is shown in figure 7. At the base of these projecting structures on the dorsal aspect (figs. 7, 8, $\mathrm{n}$ ) is a slender transverse sclerotized bar. On the ventral aspect also is found a sclerotized structure which extends transversely, surrounding the base of the projections, and widens mesally to form an inverted $\mathrm{V}$ (fig. 7, o).

The cephalo-pharyngeal skeleton is withdrawn into the anterior end of the body (fig. 8) and is composed of several principal sclerites. The most anterior are the oral hooks (figs. 2, 3, oh). These are simply curved and bear on the ventro-caudal surface a tooth. This basal tooth is prominent and extends cephalo-ventrad. On the mesal margin and well toward the cephalic end of the right oral hook is a small tooth (fig. 3, r), which projects meso-caudad. The left oral hook possesses no such tooth. The intermediate sclerite which is present in the cephalo-pharyngeal skeleton of many of the higher Diptera is absent. The oral hooks articulate basally with the large basal or pharyngeal sclerite (figs. 2, 3, phs). The latter is formed of two lateral, vertical plates which are joined ventrally to form a trough which supports the pharynx. The pharyngeal sclerite is more weakly sclerotized than the remaining parts of the cephalopharyngeal skeleton. The sclerotization is strongest in the region of the point of union of the two plates and decreases as the dorsal and caudal portions are approached. The shape of these plates is rather difficult to describe but is shown in figure 2. At the ventro-cephalic end these plates are connected by a sclerotized cross-bar (s). Caudad of this cross-bar is a quadrangular opening in the trough formed by the pharyngeal sclerite. More or less joined to each lateral plate of the pharyngeal sclerite at its ventro- 
cephalic margin and extending cephalad below each oral hook is an elongate sclerite ( $t$ ). This sclerite probably aids in supporting the walls of the pharynx. The cephalic end of the pharyngeal sclerite extends cephalad to form a weakly sclerotized, curved bar which aids in strengthening the roof of the pharynx.

The anterior spiracles are absent but the posterior ones are well developed and conspicuous. These are two kidneyshaped plates on the last segment (fig. 4, sp). They are strongly convex and vary in color from a reddish-brown to a dark brown depending upon the age of the larva. The stigmal plates bear numerous wart-like protuberances (fig. 6) and on each plate there is, approximately centrally placed, a round pale spot. Surrounding these convex plates at the base is a narrow rim or collar-like structure (fig. 4, u). In most specimens this collar is slightly darker than the remainder of the plate. Each stigmal plate is slightly emarginate in the mid region of its mesal border. The surrounding rim is widest at this emargination. Slightly beyond the dorso-lateral margin of each stigmal plate there is a small spine (fig. 6, v). This structure appears to be sclerotized and is the color of the stigmal plate. The wartlike protuberances of the stigmal plates seem especially significant and these with the general shape of the larva should enable it to be recognized as a conopid. The anus lies immediately ventrad of the stigmal plates.

Puparium. - The puparium (fig. 1) is formed within the abdomen of the host and is approximately $8 \mathrm{~mm}$. in length and $5 \mathrm{~mm}$. in breadth. It is reddish or dark brown in color. The individual segments are very poorly indicated and the surface is smooth. The stigmal plates (figs. $1,5)$ retain their characteristic appearance but project outward more than in the larval stage. They are slightly smaller and the shape is not exactly as it was during the preceding stage. Figures 5 and 6 illustrate this difference in size and shape. Each stigmal plate appears as though a string had been tied around its base and the string tightened thus causing the plate to become more convex and to bulge. The wart-like protuberances are even more prominent than in the larval stage. 


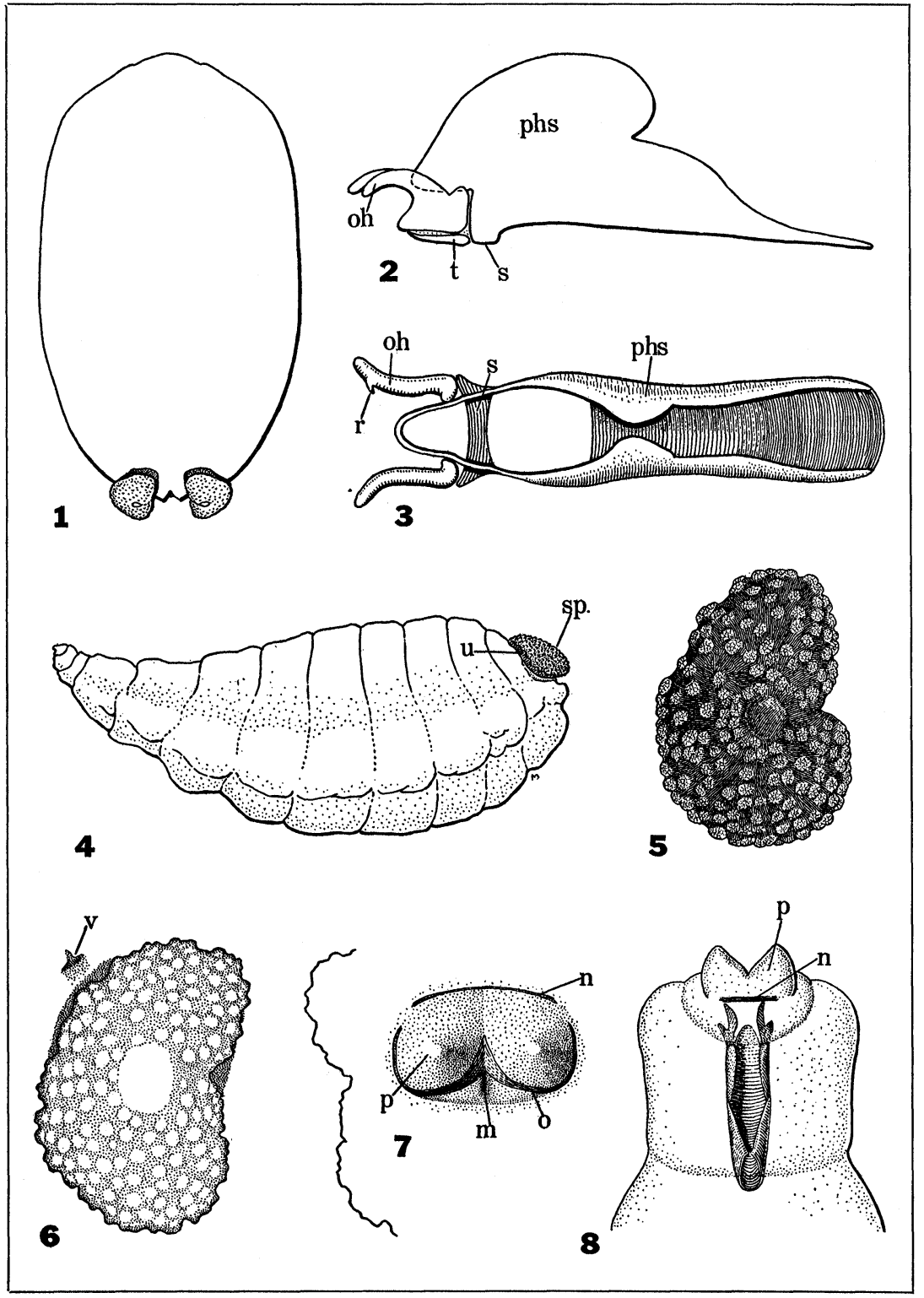

Townsend-Physocephala sagittaria 
As de Meijere (1903) has pointed out the number of wart-like protuberances on the stigmal plates varies much in the known larval forms. This writer figures the stigmal plates of the three genera known in the larval stage and there seem to be considerable differences there. The present writer is of the opinion that were known larval forms available it would be quite possible to make at least a generic key.

The only larval key known to the writer which includes this family is that of Brues and Melander (1932). These workers attempted only to separate the family from related families. They mentioned that the wart-like antennæ were tipped with a sclerotized ocellus-like ring but the present writer could find no such structure on the species considered in this paper. The conopid genera, keyed out below, have been reared from the following genera of Hymenoptera: Zodion: from Hylaeus, Odynerus, and Halictus; Sicus from Bremus; Physocephala from Apis, Xylocopa, Bremus, Bembex, Philantus, Eucera, Halictus, Megachile, and Sphingonotus. These three conopid genera have been reported only from genera of bees and wasps. Of the ten North American genera of Conopidæ, three are known as larva and the following key is offered to these:

1. Two elongate, distally tapering structures projecting from the caudo-ventral region of the body. Tracheæ extending into these structures........... Zodion. No such projecting structures present...........2.

2. Anterior spiracles present................ Sicus. Anterior spiracles absent............Physocephala.

\section{Explanation of Plate 12}

All are enlarged figures of Physocephala sagittaria (Say)

1. Dorsal aspect of puparium.

2. Left lateral aspect of cephalo-pharyngeal skeleton of larva.

3. Dorsal aspect of cephalo-pharyngeal skeleton of larva.

4. Left lateral aspect of larva.

5. Left posterior spiracle of puparium.

6. Left posterior spiracle of larva.

7. Cephalic aspect of head region of larva.

8. Dorsal aspect of anterior region of larva with cephalo-pharyngeal skeleton showing through the cuticula. 


\author{
Abbreviations \\ $\mathrm{m}-$ mouth. \\ $\mathrm{n}$ - sclerotized bar on head region. \\ $o$ - sclerotized area at base of head projection. \\ oh - oral hooks. \\ $\mathrm{p}$ - projection of head region. \\ phs - pharyngeal sclerite. \\ $\mathrm{r}$ - mesal tooth of right oral hook. \\ $\mathrm{s}$ - ventral cross-bar. \\ sp - spiracle. \\ $\mathrm{t}$ - sclerite below oral hook. \\ $\mathrm{u}$ - collar surrounding spiracle. \\ $\mathrm{v}$ - spine dorso-laterad of spiracle.
}

\title{
BIBLIOGRAPHY
}

Aldrich, J. M. (1930). American two-winged flies of the genus Stylogaster Macquart. Proc. U. S. N. M., Vol. 78, Art. 9, pp. 1-27.

Brauer, F. (1883). Die Zweiflügler des Kaiserlichen Nuseums zu Wien. III. Systematische Studien auf Grundlage der Dipterenlarven etc. Denkschr. math.-natur. Classe kais. Acad. Wissensch. Band 47: 1-100.

Brues, C. T. and Melander, A. L. (1932). The classification of insects. Bull. Mus. Comp. Zool. 73: 1-672.

Brunetti, E. (1923). The fauna of British India, Diptera. Vol. III, Conopidæ, pp. 341-342.

Frison, T. H. (1926). Contribution to the knowledge of the interrelations of the bumblebees of Illinois with their animate environment. Ann. Ent. Soc. America 19: 203-234; 1 pl. (1930). A contribution to the knowledge of the bionomics of Bremus americanorum (Fabr.). Ann. Ent. Soc. America 23: 644-665.

de Meijere, J. C. H. (1903). Beiträge zur Kenntnis der Biologie und der systematischen verwandtschaft der Conopiden. Tijd. v. Ent. $46: 144-225 ; 4$ pls.

(1912). Neue Beiträge zur Kenntnis der Conopiden Tijd. v. Ent. 55: 184-207.

Silvestri F. (1926). Descrizione di particolari individui (Myiagenii) di Termes gilvus Hagen parassitizzati da larva di Dittero. Boll. Lab. zool. Gen. agr. R. Scuola Sup. agric. Portici. 19: 3-18.

Williston, S. W. (1885). North American Conopidæ: conclusion. Trans. Connecticut Acad. Arts and Sci. 6: 388-389. 

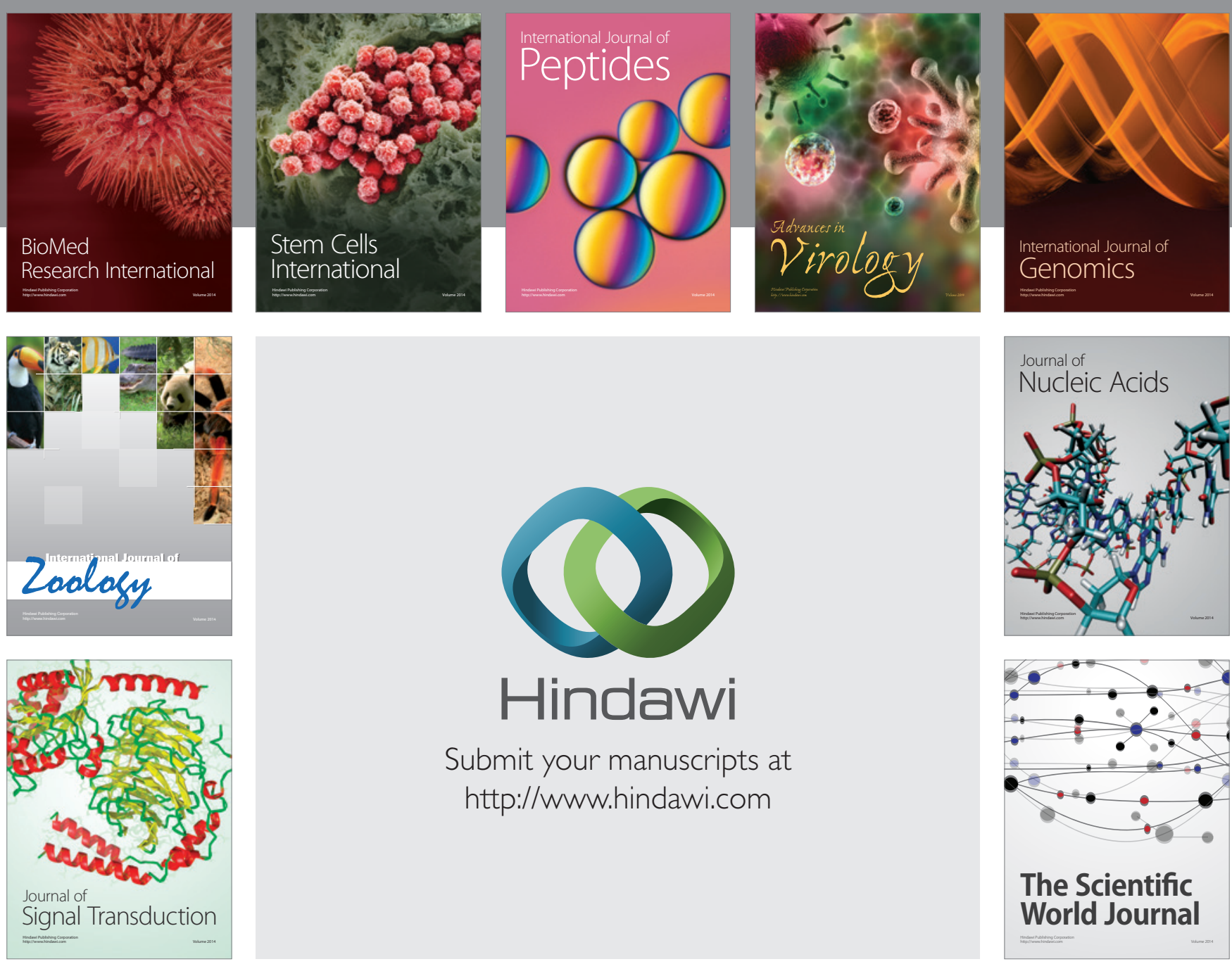

Submit your manuscripts at

http://www.hindawi.com
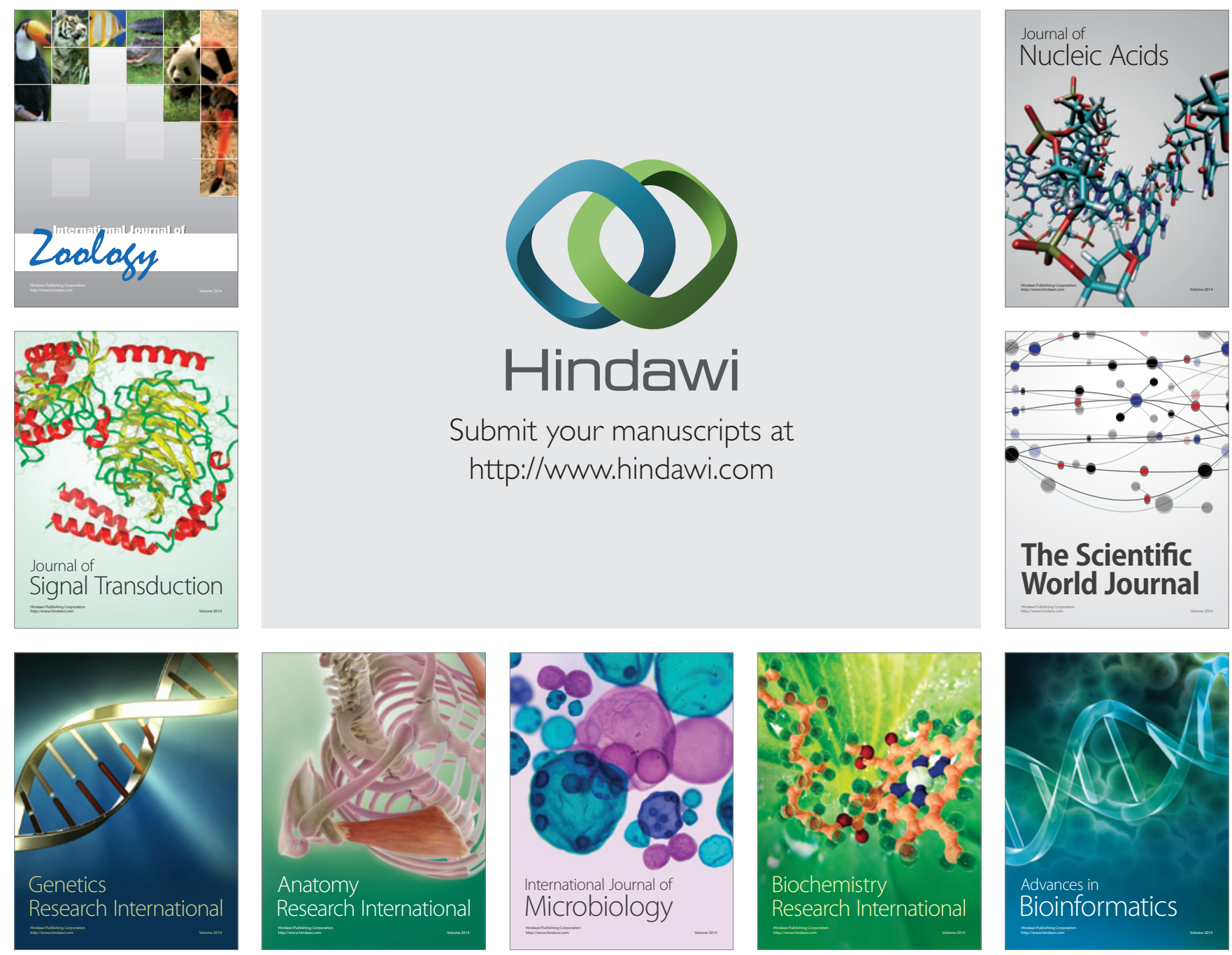

The Scientific World Journal
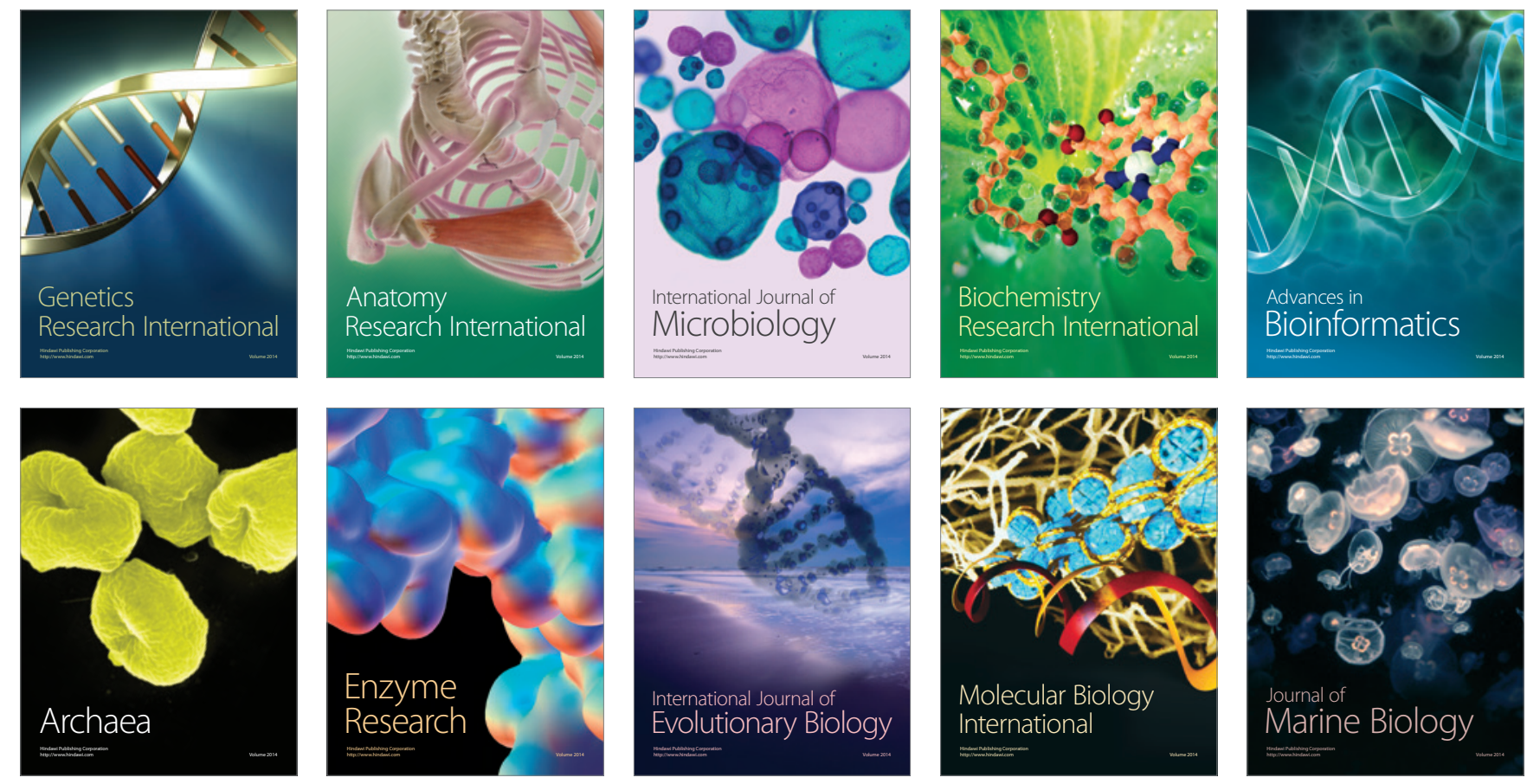